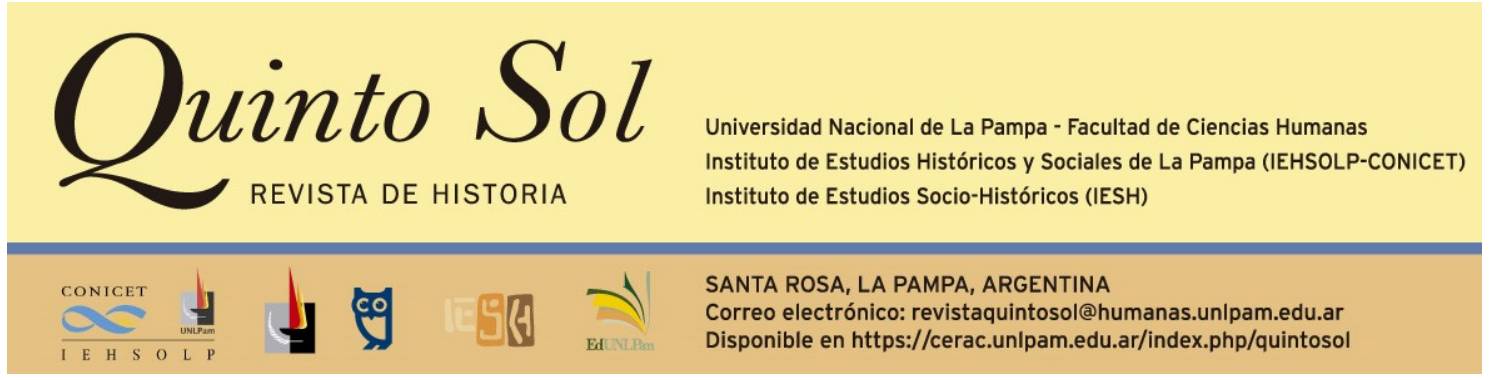

Quinto Sol, vol. 24, n 3, septiembre-diciembre 2020, ISSN 1851-2879, pp. 1-3

DOI: http://dx.doi.org/10.19137/qs.v24i3.4457

Esta obra se publica bajo licencia Creative Commons 4.0 Internacional. (Atribución-No ComercialCompartir lgual)

\title{
lan Milligan. History in the age of abundance? How the web is transforming historical research. Londres- Chicago: McGill-Queen's University Press/Montreal \& Kingston, 2019, 310 páginas.
}

\section{Emiliano Andrés Calomarde}

Universidad Nacional de Mar del Plata. Instituto de Humanidades y Ciencias Sociales. Centro de Estudios Históricos

Argentina

Correo electrónico: emiliano.mdq@hotmail.com

En History of the age of abundance? How the web is transforming historical research, Ian Milligan sostiene que enfrentamos un cambio de escala en el registro histórico que fue afectado, sobre todo, por la llegada de los repositorios nacidos digitales. En términos del autor, la edad de la abundancia o la era de la Big Data implican un acceso a los datos de una magnitud inabordable con los métodos tradicionales, pues actualmente son incluidas en la web los relatos de millones de personas que antaño quedaban por fuera de la historiografía. La preocupación de Milligan se encuentra en relación con sus trabajos previos sobre la historia canadiense y las fuentes digitales. En efecto, el libro presenta un estilo de escritura en la que predominan ejemplos de pesquisas que ponen de manifiesto los desafíos del trabajo histórico.

Los primeros dos capítulos de la obra están centrados en un problema fundante de los estudios históricos de Internet: la naturaleza moderna, dinámica y personalizada 
de la web elude inherentemente la preservación. En Exploding the Library, el primer capítulo, Milligan presenta de manera acotada, pero precisa, conceptos claves como Internet, web, hipertexto y lenguaje de marcado, siempre acompañados de una breve genealogía de los mismos. La web es definida como un conjunto de documentos conectados que pierde su efectividad si se la considera a partir de secciones pequeñas y aisladas, de allí la principal dificultad en su conservación. Según el autor, el trabajo con archivos web involucra el manejo de ciertos conocimientos técnicos ya que si no se archivan todas las páginas que se encuentran por detrás de los enlaces de un sitio, gran parte de la información se pierde. Lo mismo sucede con el lenguaje de marcado HTML que permite entender de qué manera se escriben las páginas web, ya que es aquello que codifica los recursos multimedia que se muestran en los navegadores. Sin embargo, esto no es ninguna novedad para la historia, dice Milligan, pues aprender a leer el código de marcado es similar a los estudiosos clásicos que aprenden griego o latín para comprender sus fuentes.

En el segundo capítulo, Web Archives and Their Collectors, los argumentos se tornan menos técnicos ya que el autor define la noción de archivo web a partir de su concepción tradicional, en tanto registro cultural. No obstante, es su aspecto digital lo que permite el almacenamiento, a bajo costo, de más información. En este capítulo puede comprenderse de manera cabal el interés del autor por el período que analiza ya que, como bien explica, la década de los '90 marca un punto de inflexión tanto por el mayor acceso ciudadano a los servicios de Internet, vía la web, como por la emergencia de nuevas formas de preservación de los datos. Esta es la época en que nacen distintas bibliotecas nacionales y repositorios como Internet Archive, ante los peligros de una nueva "era oscura digital" (como se caracterizó a los archivos iniciales de Internet que no fueron conservados).

A la reflexión en torno a la conservación de los registros culturales en la web, Milligan adiciona atinadamente dos cuestiones que le permiten introducir, al tiempo que tejer relaciones entre los primeros capítulos con el resto de la obra, el problema de la interpretación. La primera cuestión es el avance actual e inminente de las corporaciones como administradoras del patrimonio digital. Esto implica que, en la medida en que las ganancias disminuyan, también lo hará su compromiso con el contenido en línea. El segundo punto refiere a la representatividad, el quehacer histórico en la web debe tener en cuenta, según el autor, las brechas digitales en tanto desigual acceso en términos de clase, nación, edad o género.

El énfasis de Milligan por homologar el concepto de archivo web al tradicional comienza a esfumarse a lo largo de los siguientes dos capítulos del libro (Accessing the Records of Our Lives \& Unexpected Needles in Big Haystacks) pues allí queda en evidencia la singularidad y complejidad del trabajo con las fuentes nacidas digitales como así también las habilidades computacionales y las reformas pedagógicas necesarias para abordar esta nueva era de la investigación. Según el autor, es menester reconocer a nivel técnico cómo se configuran los archivos web en tanto documentos que involucran una gran diversidad de recursos dispares (imágenes, videos, sonidos y más). Milligan ilustra esta premisa examinando las historias de los hipervínculos de los partidos canadienses para ver de qué manera los metadatos brindan información sobre cuáles sitios web recibieron la mayoría de enlaces entrantes o cuáles se encontraban mejor posicionados.

Para el autor el análisis de las páginas web no se limita a su contenido visible 
(que depende en gran medida de la forma de preservación) sino a la posible reconstrucción de las redes de conexiones que las definieron en un momento dado. En consecuencia, los archivos web son facsímiles imperfectos de su original, ya que el investigador navega usando diferente hardware o estándares HTML. A su vez, un asunto no menor para Milligan es el conocimiento en torno a los algoritmos que permiten, en la era de la Big Data, ordenar los datos para su posterior interpretación. En palabras del autor, mientras es cada vez más difícil abordar este tipo de investigación sin herramientas algorítmicas, se vuelve ineludible también conocer su funcionamiento y reflexionar en torno a sus límites, posibilidades y sesgos.

El quinto capítulo del libro (Welcome to GeoCities, Population Seven Million) es un estudio de caso en el que Milligan explora los problemas técnicos, epistemológicos y éticos del trabajo con archivos web. Para ello analiza Geocities.com, un servicio que permitió a los usuarios, desde 1994 a 2009, construir de forma rápida y sencilla sus propios sitios web organizados en barrios y suburbios según su temática afín (familias, mascotas, política, videojuegos, etc.). El autor describe el funcionamiento de esta comunidad virtual, sus transformaciones a lo largo de los años y su decaída final, siempre en relación con la historia misma de Internet y la web. A lo largo del capítulo se interroga sobre las formas de preservación de los datos (en este caso gracias a la labor del repositorio Internet Archive), la manera en que es posible ordenar e interpretar los millones de registros culturales de Geocities y sus implicancias éticas. Esta sección puede considerarse una de las más valiosas de la obra ya que es allí donde Milligan deja en claro bajo cuáles paradigmas y de qué manera es posible llevar a cabo una investigación histórica sobre una porción de la web.

Finalmente, el sexto capítulo del libro, The (Practical) Historian in the Age of Big Data, es una apuesta didáctica y filosófica hacia el futuro de los estudios históricos en el cual se exploran las tendencias y el estado actual de desarrollo de las herramientas digitales e innovaciones metodológicas para el análisis de archivos web. En este punto el autor reconoce las dificultades que implica esta nueva forma de investigación, sobre todo por la poca proliferación de tales temáticas en los currículos y capacitaciones. No obstante, como en toda la obra, Milligan interpela a los investigadores a experimentar con distintas herramientas digitales, desde softwares de código abierto y fácilmente asequibles hasta el trabajo con las líneas de comando, que permiten el rastreo y análisis de grandes cantidades de archivos nacidos digitalmente. Esta es una de las razones que le permiten a Milligan deducir un futuro prometedor al desarrollo de los estudios de los archivos web.

El autor está convencido de que mientras mayor sea el esfuerzo por alcanzar una alfabetización computacional básica, es decir la capacidad de manipular algoritmos y códigos que produjeron los archivos web, las preguntas de investigación serán cada vez más sofisticadas, individuales y exclusivas. Esto no quiere decir, según Milligan, que la historia de la web nos permita alcanzar una historia o una ciencia social más "científica" pues para él, la subjetividad del investigador seguirá atravesando, más que nunca, los recortes del análisis. Es una tarea a futuro reconocer el "giro digital" que se avecina, no para desterrar los métodos de investigación tradicionales, sino porque las herramientas algorítmicas posiblemente guiarán y moldearán las formas de producir conocimientos en los años venideros. 